\title{
Critical Assessment of Myelography Practices: A Call for Rational Guideline Revision
}

\author{
(D).M. Shah, DP.G. Kranz, (D). Anzai, DT.A. Hutchins, (D)W.N. Gibbs, (D) N. Pierson, DB.W. Aldred, and (D) R.H. Wiggins
}

\begin{abstract}
BACKGROUND AND PURPOSE: Patient preparation for myelography and postprocedural monitoring varies widely between practices, despite published guidelines. Our aim was to examine the current practice variations in discontinuing reportedly seizure thresholdlowering medications before myelography and to assess the reported incidence of postmyelographic seizures.
\end{abstract}

MATERIALS AND METHODS: An e-mail survey was sent to American Society of Neuroradiology members concerning the number of postmyelographic seizures experienced in the past 5 years, the presence of an institutional policy for discontinuing seizure threshold-lowering medications, and the type of myelographic contrast used. We compared the postmyelographic seizure frequency in the responses.

RESULTS: Of 700 survey responses, 57\% reported that they do not discontinue seizure threshold-lowering medications before myelography. Most (97\%) indicated never having a patient experience a seizure following myelography. The number of postmyelographic seizures between those who discontinue seizure threshold-lowering medications and those who do not was not statistically significant (OR $=2.13$; $95 \% \mathrm{Cl}, 0.91-4.98 ; P=.08)$. Most (95\%) reported using nonionic hypo-osmolar agents.

CONCLUSIONS: Survey results revealed widely variable practices for patient myelography preparation and postprocedural monitoring. We found no difference in reported seizures between those who discontinued seizure threshold-lowering medications and those who did not. In light of our findings, we propose that discontinuing reportedly seizure threshold-lowering medications is not warranted with the current nonionic water-soluble contrast agents and may be potentially harmful in some instances. This work supports revision of existing recommendations to withhold such medications before myelography.

ABBREVIATION: STLM = seizure threshold-lowering medications

M yelography with intrathecal injection of iodinated contrast remains a valuable imaging test for patients with neurologic deficits, particularly those having contraindications to MR imaging. ${ }^{1}$ Potential complications of myelography include infection, hemorrhage, nerve injury, and, reportedly, postmyelographic seizures in patients taking certain medications. Published ${ }^{1}$ and pending ${ }^{2}$ American College of Radiology-American Society of Neuroradiology-Society of Pediatric Radiology (ACR-ASNR-SPR) clinical practice parameters, which are based on myelographic contrast agent package

Received July 16, 2018; accepted after revision August 25

From the Department of Radiology and Imaging Sciences University (L.M.S., Y.A., T.A.H., N.P., B.W.A., R.H.W.), Utah Health Sciences Center, Salt Lake City, Utah; Department of Radiology (P.G.K.), Duke University Medical Center, Durham, North Carolina; and Department of Radiology (W.N.G.), Keck Medical Center of University of Southern California, Los Angeles, California.

Please address correspondence to Lubdha M. Shah, MD, University of Utah Department of Radiology, 30N 1900E, Room 1A071, Salt Lake City, Utah 84132; e-mail: lubdha.shah@hsc.utah.edu; @lubdha_shah

三 Indicates article with supplemental on-line tables.

http://dx.doi.org/10.3174/ajnr.A5867 inserts $^{3,4}$ and case reports, ${ }^{5-27}$ recommend screening of the patient's medication list and discontinuation of those medications that reportedly lower the seizure threshold (phenothiazine derivatives, monoamine oxidase inhibitors, tricyclic antidepressants, CNS stimulants, and psychoactive drugs) to reduce the theoretic risk of postmyelographic seizures.

Adherence to these recommendations varies; some centers discontinue seizure threshold-lowering medications (STLMs) before myelography, while others do not. At many institutions, only anticoagulants are discontinued, and no extended postprocedural patient monitoring is performed. However, the common practice in many institutions is to stop STLMs up to 48 hours before and 24 hours after the myelogram and monitor patients at least 4 hours postprocedure. These recommendations are based on anecdotal evidence and literature based on the use of older iodinated contrast agents, now outdated, given the current widespread use of nonionic myelographic contrast agents. ${ }^{28}$ There has been considerable clinical experience in safely performing myelography without complications using the newer, less neurotoxic iodin- 


\begin{tabular}{|c|c|c|c|c|c|}
\hline Type of Practice & Discontinue STLMs & $\begin{array}{c}\text { Observed Postmyelographic } \\
\text { Seizure }\end{array}$ & $\begin{array}{l}\text { 30-Min to } 2-\mathrm{Hr} \\
\text { Postmyelographic } \\
\text { Monitoring }\end{array}$ & $\begin{array}{l}\text { Nonionic Hypo- } \\
\text { Osmolar } \\
\text { Contrast }\end{array}$ & $\begin{array}{l}>15 \mathrm{Yr} \text { in } \\
\text { Practice }\end{array}$ \\
\hline Academic $(n=281)$ & $59 \%(167)$ & $4 \%(12)$ & $69 \%(193)$ & $93 \%(260)$ & $46 \%(129)$ \\
\hline Private practice $(n=316)$ & $52 \%(163)$ & $2.2 \%(7)$ & $55 \%(175)$ & $97 \%(304)$ & $66 \%(207)$ \\
\hline Hybrid $(n=100)$ & $67 \%(67)$ & $4 \%(4)$ & $54 \%(54)$ & $92 \%(92)$ & $47 \%(47)$ \\
\hline
\end{tabular}

a Percentage (No.) of practitioners in different practice group settings and whether they discontinued STLMs, observed a postmyelographic seizure, performed 30-min to 2-hr postmyelographic monitoring, used nonionic hypo-osmolar contrast, and have been in practice $>15 \mathrm{yr}$.

ated contrast agents. ${ }^{22}$ Although there are a few case reports of complications, particularly seizures, ${ }^{6,19,21,25}$ it is not clear whether the seizure was an unrelated, idiosyncratic reaction due to the myelographic agent itself or due to a drug interaction with a reportedly STLM. There is no strong evidence supporting an increased risk of seizures after exposure to the current, nonionic myelographic contrast agents while the patient is on these medications.

Hundreds of commonly used medications fall into this category of STLMs, and the task of identifying and discontinuing these medications at least 24 hours before the myelography and then resuming them to the therapeutic levels after the procedure is challenging clinically and potentially harmful to the patient. Often the procedure has to be rescheduled after the patient arrives at the hospital if these STLMs have not been discontinued. This rescheduling causes direct and indirect financial burdens to the patients, and the potential for undertreating comorbid conditions while these medications are withheld. Cancelling and rescheduling procedures can also have a negative impact on the health care institution. ${ }^{29}$ The patient may have emotional stress and a negative perception of the quality of care.

The purpose of this investigation was to study the practice variability of discontinuing STLMs before myelography by means of a survey of the ASNR membership. We compared the number of reported seizure events by practitioners who withhold these medications with the number of reported seizure events by those who do not withhold these medications. In addition, we reviewed the literature on which recommendations are based, to critically assess the risks and benefits of this practice. ${ }^{1}$

\section{MATERIALS AND METHODS}

The myelogram survey was e-mailed to 6300 members of the American Society of Neuroradiology (with approval from the American Society of Neuroradiology Board of Directors) in December 2017 and was open until May 2018. The survey introduction stated the goals of this project: "The current clinical practice for myelography, including patient preparation and postprocedural monitoring, seems to vary widely among institutions. Although the ACR-ASNR-SPR clinical practice parameters suggest careful evaluation of the risk-benefit assessment, there is no clear evidence to support the discontinuation of the reported STLMs before myelography, particularly with the newer contrast agents. The purpose of this survey is to obtain the current practice patterns of neuroradiologists in different practice settings with the goal of updating practice parameters that help guide practitioners who perform these procedures." The survey was designed to be brief to increase the likelihood of completion and response. We estimated that this would take $<2$ minutes. It included questions on the number of reported postmyelographic seizures in the past
5 years, their practice of discontinuing STLMs (phenothiazine derivatives, monoamine oxidase inhibitors, tricyclic antidepressants, CNS stimulants, and psychoactive drugs), and the type of myelographic contrast used (On-line Table 1). We compared the number of reported postmyelographic seizures by members who routinely discontinued STLMs versus those who did not routinely discontinue STLMs.

\section{Statistical Analysis}

A $2 \times 2$ cross-tabulation table of the number of patients in an institution with postmyelographic seizures whose medications were stopped and the number of patients in an institution with postmyelographic seizures whose medications were not stopped was formulated. This was then tested for statistical significance using a $\chi^{2}$ test. ${ }^{30}$ Contingency tables with $\chi^{2}$ tests were also performed among types of practices, years in practice, the method of patient preparation, and whether the practitioners observed a postmyelographic seizure. $P<.05$ was considered a statistically significant difference between groups, and analysis was conducted using STATA 15.1 (StataCorp, College Station, Texas).

\section{RESULTS}

There were 700 responses to the survey during 6 months, with a response rate of $11.1 \%$. The summary of the survey results is listed in the Table. Of note, a few responders did not answer some of the questions, so the subsets of the questions combining these answers have fewer total numbers of responses. Most of those responding (398; 57\%) reported that they do not routinely discontinue medications before myelography. Most $(677 ; 97 \%)$ responders reported that they never had a patient who experienced a seizure following myelography. Most $(422 ; 61 \%)$ respondents indicated that they monitored patients between 30 minutes and 2 hours following the myelographic procedure. Most $(656 ; 94 \%)$ also reported using a nonionic hypoosmolar agent (ie, Isovue-M [iopamidol; Bracco, Princeton, New Jersey] or Omnipaque [iohexol; GE Healthcare, Piscataway, New Jersey]). The iso-osmolar agent Visipaque (iodixanol; GE Healthcare) was used less frequently $(37 ; 5.3 \%)$. Regarding the types of practice, 316 responders $(45 \%)$ indicated that they were in private practice, while 282 responders (40\%) reported that they were in an academic practice. Most respondents also reported being in practice for $>15$ years $(383 ; 55 \%)$.

Twenty-three (3.3\%) respondents indicated that they had observed at least 1 patient having a seizure after myelography in the past 5 years. Of these 23 practitioners reporting at least 1 seizure, 14 (61\%) specified that they had stopped any seizure threshold-lowering medications before the procedure, and 9 (39\%) did not stop those medications before the myelographic procedure. There was a 2.13 odds ratio (95\% confidence interval, $0.91-4.98 ; P=.08$ ) of a practitioner 
reporting a seizure when STLMs were withheld compared with a practitioner who did not withhold medications, though the difference was not statistically significant. Most (15/23, 65\%) of these respondents monitored patients for 30 minutes to 2 hours.

There was no statistically significant difference between the reported number of postmyelographic seizures and the type of nonionic contrast used-that is, hypo-osmolar or iso-osmolar $(P=.48)$. No statistically significant difference was observed in the following comparisons: practice type and STLM discontinuation $(P=.14)$, practice type and postmyelographic seizure observation $(P=.34)$, years in practice and STLM discontinuation $(P=.62)$, and years in practice and postmyelographic seizure observation $(P=.28)$ (On-line Table 2$)$.

\section{DISCUSSION}

The use of myelography has declined dramatically in the past 3 decades, but it remains a vital imaging technique for assessing patients with contraindications to MR imaging, for preoperative orthopedic surgical planning, for radiation treatment planning, and for possible demonstration of a cerebrospinal leak. ${ }^{1,2}$ Physicians must weigh the benefits of performing myelography with the theoretic risk of seizures in patients who must temporarily discontinue STLMs. A survey of the ASNR membership allowed us to collect data on the current practice variations among diverse practice settings and estimate the reported incidence of postmyelographic seizure among those practitioners who withhold these medications and those who do not. Our review of the literature provided insight into the origin of withholding STLMs.

Metrizamide (Amipaque; Nyegaard and Company, Oslo, Norway), the first nonionic water-soluble contrast medium for myelography, was introduced in the early 1970s. ${ }^{31,32}$ It was the first such agent to gain wide acceptance, replacing oil-soluble contrast agents such as iodophenylundecylic acid (Pantopaque (Lafayette Pharmacal Company); GlaxoSmithKline, Brentford, $\mathrm{UK}$ ) and allowing examination of the entire spinal subarachnoid space with much less chance of subsequent arachnoiditis. The adverse effects of metrizamide were milder than those with the ionic water-soluble agents, consisting of mainly nausea and vomiting (10\%-20\% of cases), though there were reports of more serious adverse effects, including seizures $(0.2 \%-0.6 \%)$, hallucinations, and aseptic meningitis. ${ }^{33,34}$ Complications from metrizamide are often dose-related, resulting from excessive intracranial concentrations of the drug. ${ }^{12,18,35-38}$ The mechanism of metrizamide neurotoxicity is postulated to be cerebral glucose metabolism interference. ${ }^{11,37,39}$ The recognized risk factors for metrizamide myelography were seizure disorder, STLMs, dehydration, diabetes, and age, ${ }^{40}$ and these risk factors were not dose-dependent. $^{33,41}$ Given such neurologic complications, withholding STLMs for at least 48 hours before metrizamide myelography was recommended. ${ }^{42}$

Nonionic contrast media, such as iohexol (Omnipaque), iopamidol (Isovue-M), and iodixanol (Visipaque) ${ }^{43,44}$ have replaced metrizamide and are less neurotoxic than ionic, water-soluble contrast agents, causing fewer adverse effects than agents previously used to evaluate the spine and intrathecal contents. ${ }^{22}$ The reported cases of postmyelographic seizure with nonionic, watersoluble contrast in the past decade have been very rare. Although animal studies have shown iopamidol to be more epileptogenic than metrizamide ${ }^{45}$ and the excitative neurotoxic potential of iodixanol, ${ }^{46}$ clinical trials of these newer nonionic agents have shown them to be safe and effective, with fewer adverse effects

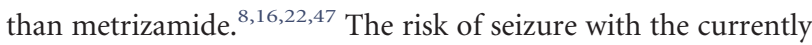
used contrast media is reported to be in the range of $0.093 \%-$ $0.847 \% .{ }^{19,48}$ Review of the literature revealed only case reports of seizure activity after myelography with iopamidol ${ }^{13,21}$ and iohexol (On-line Table 3). 5, 7,15,26 In patients with epilepsy, the risks and benefits of myelography, even with the newer agents, must be weighed against the risk of inducing seizures or status epilepticus because there have been reports of seizures induced by nonionic contrast myelographic agents in patients with epilepsy. ${ }^{13,19,20}$ Given the rare incidence of postmyelographic seizures with the newer contrast agents, it is difficult to perform a prospective randomized controlled study. In a 2005 survey of the ASNR membership on myelography practice patterns and complications, $88 \%$ of 351 respondents reported no seizures postmyelographic and $12 \%$ reported $1-2$ seizures in the past 5 years. ${ }^{49}$ In our ASNR survey, $23(3.3 \%)$ of 700 respondents indicated that they had observed at least 1 patient having a postmyelographic seizure in the past 5 years.

Case reports have described seizures occurring $<12$ hours after the myelographic procedure. ${ }^{13,50}$ Nonionic, water-soluble radiographic contrast agents such as iohexol and metrizamide penetrate the CNS spaces and are eliminated from the subarachnoid space during 2-8 hours. ${ }^{33}$ Most of the subjective reactions have occurred in the first 8 hours after cervical and thoracic myelography, ${ }^{51}$ while in a study on lumbar myelography, half of all subjective reactions occurred in the first 9 hours. ${ }^{22}$ Almost all electroencephalography changes after cervical and thoracic myelography occurred within 6 hours $^{51}$ and at 24 hours after lumbar myelography. The Nakstad et $\mathrm{al}^{51}$ study describing electroencephalography changes did not indicate whether the patients were on STLMs, but the authors stated that patients continued to take other medications. ${ }^{51}$ More than half $(61 \%)$ of the survey respondents indicated that they monitored patients for between 30 minutes and 2 hours following the myelographic procedure, which was the length of time that most (65\%) of those reporting postmyelographic seizures described monitoring patients postmyelography.

Some case reports offered different rationales for postmyelographic seizures. In most reported cases of major motor seizures with nonionic myelographic media, $\geq 1$ of the following factors was present: deviations from the recommended procedure, use in patients with a history of epilepsy, over-dosage, ${ }^{14}$ intracranial entry of a bolus or premature diffusion of a high concentration of the medium, failure to maintain elevation of the head during or postprocedure, and/or excessive patient movement or straining. ${ }^{52}$ In 1 case report of iopamidol $300 \mathrm{~mol} / \mathrm{L}$-induced seizures, the authors proposed that the patient's underlying alcoholism resulted in an increase in blood-brain barrier micropinocytic activity, with associated increased permeability to the myelographic iodinated material, and resulted in postmyelographic seizures. ${ }^{13}$ Some investigators have suggested that the incidence of complications such as meningeal and radicular irritation may be related to the dose of the contrast medium. ${ }^{10,24}$ On the other hand, Lipman et $\mathrm{al}^{21}$ reported 2 cases of seizure after iopamidol myelography 
in a retrospective series of 236 consecutive patients with recommended doses. ${ }^{21}$ There may be a correlation between the upper level of visible contrast medium and the incidence of adverse reactions. ${ }^{10}$ Klein et $\mathrm{al}^{19}$ found a lower incidence of seizure induction for lumbar myelography than for myelography that included the cervical subarachnoid space. In a retrospective review of cervical myelograms performed with iopamidol-300 mol/L ( $\sim 12 \mathrm{~mL})$ between 2011 and 2016, however, we had no documentation of seizure activity within 24 hours of the procedure. ${ }^{53}$ The higher incidence of neurologic complications with cervical myelography compared with lumbar myelography has been postulated to be caused by changes in the transmitter metabolism, resulting in overexcitability of the neurons, ${ }^{54}$ and may not require breakdown of the BBB because contrast media may enter the extracellular space by passive diffusion through the pia mater. ${ }^{19}$

In many of these case reports describing postmyelographic seizures, it was either not specified whether the patients were on a reportedly STLM or no association was discussed. Two case reports of seizure activity with metrizamide and iohexol included the concomitant use of an agent that lowers the seizure threshold. ${ }^{7,17}$ However, several animal experiments ${ }^{23,45,55-57}$ have failed to demonstrate any excitative effect on the CNS after subarachnoid injection of iohexol, even after lowering of the seizure threshold with chlorpromazine. ${ }^{23}$ Small scale, open-label, observational investigations, though flawed, did not show an association between the concomitant administration of contrast agents and STLMs and an increased risk of seizures. ${ }^{58-60}$ In a prospective, placebo-controlled trial, Standnes et $\mathrm{al}^{59}$ evaluated the potentiation of seizures with neuroleptic drugs (ie, levomepromazine) in conjunction with metrizamide myelography and found electroencephalography deterioration in $22 \%$ of the patients, with no difference in electroencephalography results between the 2 groups. In a retrospective review of cervical myelography performed with iopamidol-300 mol/L, at the University of Utah, 40\% (73/185) had documentation of at least 1 of the reportedly STLMs; however, no seizures were observed in either group. $^{53}$

Although there have been no well-designed studies to confirm an increased seizure risk in patients undergoing myelography who take STLMs, some practitioners recommend that such medications be avoided 48 hours before and 24 hours after administration of myelographic contrast medium. ${ }^{61}$ Many institutions have initiated protocols to withhold these medications preprocedure despite no high-level evidence to advocate this practice. A literature review by Fedutes and Ansani ${ }^{48}$ recommended that any medication associated with seizure threshold lowering may potentially increase the risk of seizures with metrizamide or iohexol. However, they stated that the available data are anecdotal. The authors made this recommendation based on the studies showing that the nonionic, water-soluble contrast media agents themselves may lower the seizure threshold, and therefore, that there may be a potential increase in seizure risk when these contrast agents are administered concomitantly with medications that carry the same risk. Without providing any data, the authors recommended discontinuing medications associated with seizure activity before and immediately following myelography. ${ }^{48}$

Expert opinions and practice patterns vary. Neurologists specializing in epilepsy management in some institutions consider the current myelographic contrast agents to have a very low epileptogenic potential and do not prescreen for or withhold STLMs. ${ }^{62}$ They modify the procedure (eg, use a smaller volume of contrast material or avoid direct intracranial passage) when the patient reports being on such medications during the informed consent discussion. ${ }^{62}$ There is institutional variability in policies regarding discontinuing STLMs, with some having no published guidelines and others having internal or individual experiential policies. Together with community standards, these define regional standard of care. The authors in our study represent 3 institutions with varying practices regarding discontinuing STLMs. The 2005 ASNR myelography survey revealed that most of the seizures $(88 \%)$ were in patients who were not taking potentially epileptogenic drugs and most (78\%) occurred in practices that screen for such drugs. ${ }^{49}$ The trend has changed in the past decade because more than half (57\%) of the respondents in our recent ASNR survey indicated that they do not routinely discontinue these medications before myelography. Of the respondents in the 2005 survey whose patients experienced seizures, $40 \%$ indicated that these patients had a history of seizures and $14 \%$ reported that the patients had been taking potentially epileptogenic drugs. In our recent ASNR survey, there was no statistically significant difference between the reported number of postmyelographic seizures by those who discontinued STLMs and by those who did not. There were no greater odds of a practitioner reporting a seizure when STLMs were not withheld compared with when they were withheld $(\mathrm{OR}=2.13, P=.08)$. That the number of postmyelographic seizures were reported more frequently (14/ 23 , or $61 \%$ ) when STLMs were withheld runs counter to the idea that holding such medications reduces the risk of seizures. Rather, it indicates that the seizure risk is the same regardless of the discontinuation of the STLMs and is supported by the lack of statistical significance in the difference between the groups.

The package inserts for iohexol and iopamidol do not recommend the concomitant use of the contrast agent and "drugs which lower the seizure threshold, especially phenothiazine derivatives, including those used for their antihistamine properties ..." and allow clinicians to make decisions for each patient individually, "while the contributory role of these medications has not been established, the use of such drugs should be based on physician evaluation of potential benefits and potential risks." ${ }^{3,4}$ Such statements also do not make it easy to formulate a succinct list of medications to discontinue before myelography, which is particularly exasperating because new drugs that potentially decrease the seizure threshold are frequently introduced by the pharmaceutical industry. From informal discussions with radiologists at other institutions and survey responders, we believe the STLM list is not uniform. Adherence to the list may be impractical, and there may be health risks related to discontinuing medications used to treat comorbid conditions. ${ }^{63}$ For example, abruptly discontinuing antipsychotic medications can cause abnormal motor syndromes and greater mood instability. Difficulty in compliance leads to many patients being rescheduled, resulting in delay of care, poor use of resources, and decreased patient and referring physician satisfaction.

Our study has a few limitations. With survey research, there may be a self-reporting bias because respondents may not feel

AJNR Am J Neuroradiol 39:2378-84 Dec 2018 www.ajnr.org 
encouraged to provide accurate answers or responses that present them in an unfavorable manner. There may also be a recall bias, with responders not accurately recalling incidences of postmyelographic seizures. We had a relatively low response rate of $11 \%$ to the survey, which may be due to a limited number of ASNR members routinely performing myelograms. The members with myelography experience who did not respond may introduce a nonresponse bias. ${ }^{64}$ Those responders to the survey may have different practice characteristics, which may not be representative of the ASNR membership or neuroradiologists in the community. This coverage error of discrepancy between all physicians performing myelography and the sampling frame may invalidate inferences about all myelographers. The average response rate for external surveys is $10 \%-15 \%$ and that of on-line surveys is $30 \%{ }^{65}$ The response rate of our survey (11\%) has a 95\% $\pm 10 \%$ statistical accuracy. A further limitation of surveys is that respondents may not answer all questions, which we encountered. Although survey responders may perform a premyelography medication review, it is also conceivable that the patient's medication list is incomplete so that the radiologist may have been misled as to the use of STLMs. Another variability in practice is the postmyelographic observation time, which limits long-term follow-up in those who were not followed for $>2$ hours.

Given the rare occurrence of postmyelographic seizures, it is impractical to execute a randomized controlled trial or a prospective observational cohort study. The survey methodology of this study is a surrogate for an observational cohort study because it considers the experience of multiple practitioners from multiple institutions. An additional limitation of this study is the inaccuracy of estimating the real incidence of postmyelographic seizures. In our recent ASNR survey, $3.3 \%$ of the responders reported having observed a postmyelographic seizure in at least 1 patient. However, the total number of myelographic procedures that each respondent performs to estimate the true incidence is lacking. On the basis of data from the University of Utah where we performed 955 myelograms during 5 years (recognizing that this varies among institutions), we can estimate that the 700 survey respondents performed a total number of 668,500 myelographic procedures. Thus, we estimate that the incidence of postmyelographic seizures would be approximately a $0.003 \%$ incidence in a 5-year period.

The lack of high-level evidence in the literature combined with the objective analysis of data from the University of Utah and that from the multi-institutional survey leads us to propose that the theoretic increased seizure risk when a patient is on these reportedly STLMs does not outweigh the potential harm from temporary medication interruption. Furthermore, a revision of these recommendations would allow more patients access to diagnostic myelography, which is often important for clinical management. The results of this investigation will help guide local clinical practices.

\section{CONCLUSIONS}

Practice patterns for patient preparation and postmyelographic monitoring vary widely. Many practices screen for and withhold any of the hundreds of common medications that reportedly lower the threshold for seizure with concomitant myelographic contrast administration and perform extended postprocedural monitoring. This practice is based on anecdotal experience, case reports, and older contrast agents that are no longer used in most institutions. There is no compelling evidence to support this practice. We challenge the recommendation to withhold these medications: a practice with potential to harm to the patient and institution without proved benefit. We base this challenge on the results of our recent multi-institutional ASNR survey, comprehensive review of the literature, and our extensive experience performing myelographic procedures in patients on STLMs without experiencing postmyelographic seizures. We propose that discontinuing reportedly seizure threshold-lowering medications is not warranted with the current nonionic water-soluble contrast agents and that these results support an examination and revision of the current guidelines and local practices.

\section{REFERENCES}

1. ACR-ASNR Practice Guideline for the Performance of Myelography and Cisternography 2013. https://www.acr.org/-/media/ACR/Files/ Practice-Parameters/Myelog-Cisternog.pdf. Accessed October 4, 2018

2. ACR-ASNR Practice Guideline for the Performance of Myelography and Cisternography 2018. In press.

3. OMNIPAQUE (iohexol) Injection by General Electric Healthcare. https://www.accessdata.fda.gov/drugsatfda_docs/label/2017/018956 s099lbl.pdf. Accessed August 23, 2018

4. ISOVUE-M (iopamidol) Injection. https://www.accessdata.fda.gov/ drugsatfda_docs/label/2017/018735s057lbl.pdf. Accessed August 23, 2018

5. Ahmed I, Pepple R, Jones RP. Absence status epilepticus resulting from metrizamide and Omnipaque myelography. Clin Electroencephalogr 1988;19:37-42 CrossRef Medline

6. Alimohammadi H, Abdalvand A, Safari S, et al. Status epilepticus after myelography with iohexol (Omnipaque). Am J Emerg Med 2012;30:2092.e1-3 CrossRef Medline

7. Altschuler EM, Segal R. Generalized seizures following myelography with iohexol (Omnipaque). J Spinal Disord 1990;3:59-61 Medline

8. Baccarini L, de Nicola D, Gasaprini D, et al. lopamidol (B 15000), a nonionic water-soluble contrast medium for neuroradiology, Part I: results of a clinical trial for myelography. Neuroradiology 1982;23: 81-84 CrossRef Medline

9. Baker RA, Hillman BJ, McLennan JE, et al. Sequelae of metrizamide myelography in 200 examinations. AJR Am J Roentgenol 1978;130: 499-502 CrossRef Medline

10. Bassi P, Cecchini A, Dettori P, et al. Myelography with iopamidol, a nonionic water-soluble contrast medium: incidence of complications. Neuroradiology 1982;24:85-90 CrossRef Medline

11. Bertoni JM, Schwartzman RJ, Van Horn G, et al. Asterixis and encephalopathy following metrizamide myelography: investigations into possible mechanisms and review of the literature. Ann Neurol 1981;9:366-70 CrossRef Medline

12. Butler MJ, Cornell SH, Damasio AR. Aphasia following pluridirectional tomography with metrizamide: the effect of patient position. Arch Neurol 1985;42:39-45 CrossRef Medline

13. Carchietti E, Baldassarre M, Penco T, et al. Iopamidol 300-induced epilepsy: intensive treatment and pathogenic hypothesis. Neuroradiology 1988;30:256-57 CrossRef Medline

14. Carella A, Federico F, Di Cuonzo F, et al. Adverse side effects of metrizamide and iopamidol in myelography. Neuroradiology 1982; 22:247-49 CrossRef Medline

15. Dalen K, Kerr HH, Wang AM, et al. Seizure activity after iohexol myelography. Spine (Phila Pa 1976) 1991;16:384 CrossRef Medline

16. Drayer BP, Vassallo C, Sudilovsky A, et al. A double-blind clinical trial of iopamidol versus metrizamide for lumbosacral myelography. J Neurosurg 1983;58:531-37 CrossRef Medline

17. Hindmarsh T, Grepe A, Widen L. Metrizamide-phenothiazine interaction: report of a case with seizures following myelography. Acta Radiol Diagn (Stockh) 1975;16:129-34 CrossRef Medline 
18. Killebrew K, Whaley RA, Hayward JN, et al. Complications of metrizamide myelography. Arch Neurol 1983;40:78-80 CrossRef Medline

19. Klein KM, Shiratori K, Knake S, et al. Status epilepticus and seizures induced by iopamidol myelography. Seizure 2004;13:196-99 CrossRef Medline

20. Levey AI, Weiss H, Yu R, et al. Seizures following myelography with iopamidol. Ann Neurol 1988;23:397-99 CrossRef Medline

21. Lipman JC, Wang AM, Brooks ML, et al. Seizure after intrathecal administration of iopamidol. AJNR Am J Neuroradiol 1988;9: 787-88 Medline

22. Maly P, Bach-Gansmo T, Elmqvist D. Risk of seizures after myelography: comparison of iohexol and metrizamide. AJNR Am J Neuroradiol 1988;9:879-83 Medline

23. Maly $\mathrm{P}$, Olivecrona $\mathrm{H}$, Almén $\mathrm{T}$, et al. Interaction between chlorpromazine and intrathecally injected non-ionic contrast media in non-anaesthetized rabbits. Neuroradiology 1984;26:235-40 CrossRef Medline

24. Noda K, Miyamoto K, Beppu H, et al. Prolonged paraplegia after iohexol myelography. Lancet 1991;337:681 Medline

25. Singh S, Rajpal C, Nannapeneni S, et al. Iopamidol myelographyinduced seizures. MedGenMed 2005;7:11 Medline

26. Tahta K, Ozgen T, Berker M, et al. Status epilepticus following iohexol myelography. Neuroradiology 1993;35:322-23 CrossRef Medline

27. Vossler DG, Wright SJ Jr. Convulsive status epilepticus following intrathecal iopamidol administration. J Epilepsy 1994;7:18-20 CrossRef

28. Hanus PM. Metrizamide: a review with emphasis on drug interactions. Am J Hosp Pharm 1980;37:510-13 Medline

29. Maimaiti N RA, Aghaie LA. Economic impact of surgery cancellation in a general hospital, Iran. Ethiopian Journal of Health Development https://www.ajol.info/index.php/ejhd/article/view/167749. Accessed August 23, 2018

30. Pepe MS. The Statistical Evaluation of Medical Tests for Classification and Prediction. New York: Oxford University Press; 2003

31. Skalpe IO, Amundsen P. Thoracic and cervical myelography with metrizamide: clinical experiences with a water-soluble, nonionic contrast medium. Radiology 1975;116:101-06 CrossRef Medline

32. Skalpe IO, Amundsen P. Lumbar radiculography with metrizamide: a nonionic water-soluble contrast medium. Radiology 1975;115: 91-95 CrossRef Medline

33. Junck L, Marshall WH. Neurotoxicity of radiological contrast agents. Ann Neurol 1983;13:469-84 CrossRef Medline

34. Centeno RS, Sovak M, Hackney DB, et al. Brain changes on computed tomography following metrizamide myelography: significance and therapeutic implications. Spine (Phila Pa 1976) 1986;11: 509-12 CrossRef Medline

35. Drayer BP, Rosenbaum AE. Metrizamide brain penetrance. Acta Radiol Suppl 1977;355:280-93 Medline

36. Ropper AH, Chiappa KH, Young RR. The effect of metrizamide on the electroencephalogram: a prospective study in 61 patients. Ann Neurol 1979;6:222-26 CrossRef Medline

37. Caillé JM, Guibert-Tranier F, Howa JM, et al. Cerebral penetration following metrizamide myelography [in French]. J Neuroradiol 1980;7:3-12 Medline

38. Solti-Bohman L, Bentson JR. Comparative advantages of small- and large-dose metrizamide myelography. AJR Am J Roentgenol 1983; 141:825-28 CrossRef Medline

39. Ekholm SE, Reece K, Coleman JR, et al. Metrizamide: a potential in vivo inhibitor of glucose metabolism. Radiology 1983;147:119-21 CrossRef Medline

40. Steiner E, Simon JH, Ekholm SE, et al. Neurologic complications in diabetics after metrizamide lumbar myelography. AJR Am J Roentgenol 1986;146:1057-60 CrossRef Medline

41. Skalpe IO. Adverse effects of water-soluble contrast media in myelography, cisternography and ventriculography: a review with special reference to metrizamide. Acta Radiol Suppl 1977;355: 359-70 Medline
42. Meador K, Hamilton WJ, El Gammal TA, et al. Irreversible neurologic complications of metrizamide myelography. Neurology 1984; 34:817-21 CrossRef Medline

43. Maly P, Sundgren P, Bååth L, et al. Neural tolerance of the non-ionic dimers iodixanol and iotrolan and the non-ionic monomer iopamidol during myelography in non-anaesthetised rabbits. Acta Radiol 1995;36:644-48 Medline

44. La Noce A, Bertani F, Lorusso V, et al. Preclinical safety assessment of iomeprol for injection as contrast medium for myelography. Eur J Radiol 1994;18(Suppl 1):S43-50 CrossRef Medline

45. Gonsette RE, Brucher JM. Neurotoxicity of novel water-soluble contrast media for intrathecal application. Invest Radiol 1980;15: S254-59 CrossRef Medline

46. Sundgren P, Bååth L, Maly P. CNS-effects from subarachnoid injections of iohexol and the non-ionic dimers iodixanol and iotrolan in the rabbit. Acta Radiol 1995;36:307-11 Medline

47. Witwer G, Cacayorin ED, Bernstein AD, et al. Iopamidol and metrizamide for myelography: prospective double-blind clinical trial. AJR Am J Roentgenol 1984;143:869-73 CrossRef Medline

48. Fedutes BA, Ansani NT. Seizure potential of concomitant medications and radiographic contrast media agents. Ann Pharmacother 2003;37:1506-10 CrossRef Medline

49. Sandow BA, Donnal JF. Myelography complications and current prac tice patterns. AJR Am J Roentgenol 2005;185:768-71 CrossRef Medline

50. Olsen J. Seizures after myelography with iopamidol. Am J Emerg Med 1994;12:329-30 CrossRef Medline

51. Nakstad P, Helgetveit A, Aaserud O, et al. Iohexol compared to metrizamide in cervical and thoracic myelography: a randomized double blind parallel study. Neuroradiology 1984;26:479-84 CrossRef Medline

52. Lin SM, Tsou MY, Chan KH, et al. Myoclonic seizure in the postanesthesia care unit after thoracic laminectomy. Anesth Analg 2002;95: 777-79, table of contents Medline

53. Aldred B, Pierson N, Shah L. Selective discontinuation of medications prior to myelography: Is it really necessary? American Society of Spine Radiology, February 23-26, 2017; San Diego, CA. Abstract

54. Grunert P, Pendl G. Cerebral seizure following lumbar myelography with iopamidol [in German]. Radiologe 1986;26:526-27 Medline

55. Maly P, Almén T, Golman K, et al. Excitative effects in anaesthetized rabbits from subarachnoidally injected iso- and hyperosmolar solutions of iohexol and metrizamide. Neuroradiology 1984;26:131-36 CrossRef Medline

56. Golman K, Olivecrona H, Gustafson C, et al. Excitation and depression of non-anaesthetized rabbits following injection of contrast media into the subarachnoid space. Acta Radiol Suppl 1980;362: 83-86 Medline

57. Sovak M, Ranganathan R, Kerber CW, et al. Iotrol, a new myelographic agent, 2: comparative electroencephalographic evaluation by spectrum analysis. AJNR Am J Neuroradiol 1983;4:319-22 Medline

58. Hauge O, Falkenberg H. Neuropsychologic reactions and other side effects after metrizamide myelography. AJR Am J Roentgenol 1982; 139:357-60 CrossRef Medline

59. Standnes B, Oftedal SI, Weber H. Effect of levomepromazine on EEG and on clinical side effects after lumbar myelography with metrizamide. Acta Radiol Diagn (Stockh) 1982;23:111-14 CrossRef Medline

60. Gonsette RE, Liesenborghs L. Iohexol: a new nonionic contrast medium for myelography and cisternography with markedly reduced neurotoxicity. Invest Radiol 1985;20:S32-36 Medline

61. Smith RR. Myelographic complications associated with drug interactions. AJR Am J Roentgenol 2001;177:713 Medline

62. Eames FA, Cloft HJ. Discontinuing patient medications prior to myelography. AJR Am J Roentgenol 2005;184:695 Medline

63. Howland RH. Potential adverse effects of discontinuing psychotropic drugs, Part 3: antipsychotic, dopaminergic, and mood-stabilizing drugs. J Psychosoc Nurs Ment Health Serv 2010;48:11-14 CrossRef Medline 
64. Fincham JE. Response rates and responsiveness for surveys, standards, and the journal. Am J Pharm Educ 2008;72:43 CrossRef Medline

65. Nulty DD. The adequacy of response rates to online and paper surveys: what can be done? Assessment \& Evaluation in Higher Education 2008;33:301-14 CrossRef

66. Canbay O, Bal N, Akinci S, et al. Rhabdomyolysis after intraoperative myelography. Paediatr Anaesth 2004;14:509-13
67. Kelley BC, Roh S, Johnson PL, et al. Malignant cerebral edema following CT myelogram using Isovue-M 300 intrathecal nonionic watersoluble contrast: a case report. Radiol Res Pract 2011;2011:212516

68. Sobel DF, Rowe R, Zyroff J, et al. Adverse reactions to iopamidol and iohexol myelography with special attention to headache: role of myelographic technique. Headache 1989;29:519-22

69. Teasdale E, Macpherson P. Guidelines for cervical myelography: lumbar versus cervical puncture technique. Br J Radiol 1984;57:789-93 